\title{
EFICÁCIA DO INSETICIDA INDOXACARBE NA MORTALIDADE DE Tuta absoluta (MEYRICK) (LEPIDOPTERA: GELECHIIDAE) UTILIZANDO PULVERIZAÇÃO HIDRÁULICA
}

\author{
Amanda Mirelle Bernardes ${ }^{1}$; Mauri Martins Teixeira ${ }^{1}$; Haroldo Carlos Fernandes ${ }^{1}$; André Luís da \\ Silva Quirino ${ }^{1}$; Humberto Santiago ${ }^{1}$; Christiam Felipe Silva Maciel ${ }^{1}$ \\ ${ }^{1}$ Universidade Federal de Viçosa-MG, e-mail: andre.quirino@ufv.br
}

\section{RESUMO}

Objetivou-se com o presente trabalho avaliar a mortalidade da traça do tomateiro (Tuta absoluta) após 24 e 48 horas, com a utilização do inseticida Indoxacarbe utilizando 2 doses do produto (50\% e $100 \%$ da dose recomendada). Não houve diferença significativa nos valores de mortalidade considerando os diferentes volumes de pulverização e doses utilizadas. Entretanto observou-se diferença significativa nos valores de mortalidade considerando as posições na planta, sendo os maiores valores de mortalidade encontrados nas partes externas do dossel da planta.

Palavras-chave: Tecnologia de aplicação, pulverizador costal, traça do tomateiro

\section{EFFECTIVENESS OF THE INSECTICIDE INDOXACARB IN THE MORTALITY OF Tuta absoluta (MEYRICK) (LEPIDOPTERA: GELECHIIDAE) BY USING HYDRAULIC SPRAYING}

\begin{abstract}
The objective of this work was to evaluate the mortality of the tomato leafminer Tuta absoluta 24 and 48 hours after the use of the insecticide Indoxacarb in 2 different doses (50\% and $100 \%$ of recommended dose). There was no significant difference in mortality values considering the different spray volume and doses. There was significant difference of mortality values considering the positions on the plants, with the highest mortality observed on the external parts of the plant canopy.
\end{abstract}

Keywords: Application technology, knapsack sprayers, tomato leafminer

\section{INTRODUÇÃO}

O tomate (Lycopersicon esculentum Mill.) (Solanaceae) é um fruto de grande importância econômica e social em quase todo mundo. No ano de 2009, a produção mundial de tomate alcançou valores próximos a 155 milhões de ton., numa área de 4,4 milhões de ha. Os maiores produtores mundiais são: China, Estados Unidos, Índia, Turquia, Egito, Irã, Espanha, Brasil e México (DESNEUX, 2011).
Existem diversos sistemas de produção de acordo com a finalidade do produto, podendo os frutos serem destinados à indústria para a fabricação de molhos e extratos ou para o consumo de mesa, direto ao consumidor (MEDEIROS, 2007).

Originária da América do Sul, a traça do tomateiro Tuta absoluta (Meyrick, 1917) (Lepidoptera: Gelechiidae) é considerada a mais devastadora praga desta cultura (EPPO, 2006), sendo uma das maiores famílias de microlepidópteros, com 4.600 espécies 
descritas, representando 500 gêneros (HODGES, 1998). O ciclo completo de ovo a adulto de $T$. absoluta dura de 26 a 30 dias, sendo que a fase de ovo dura entre três a seis dias. As lagartas minam as folhas, broqueiam $\mathrm{o}$ caule, perfuram $\mathrm{o}$ broto terminal e atacam os frutos, principalmente, na região de inserção do cálice, onde encontram apoio para penetrar e esta fase dura 14 dias. Ocorrem principalmente em épocas de clima seco (ALVINO, 2009).

Dependendo da época do ano as perdas podem chegar a $100 \%$ devido ao ataque nas folhas, flores, caule e principalmente nos frutos (ARNÓ \& GABARRA, 2011). Assim o elevado potencial de dano da traça contribui para o excessivo número de pulverizações na cultura do tomate segundo Iost et al. (2008).

$\mathrm{O}$ controle de T. absoluta tem sido realizado normalmente através de múltiplas aplicações de inseticidas, chegando a 36 aplicações por cultivo (OLIVEIRA et al., 2008), indesejável tanto por motivos econômicos quanto ambientais, já que as aplicações sucessivas afetam os inimigos naturais e aumentam a possibilidade de desenvolvimento de populações de pragas resistentes aos inseticidas (THOMAZINI et al., 2001).

O sistema preventivo de controle fitossanitário, além de onerar custos de produção, aumenta os riscos de intoxicação dos aplicadores e de contaminação do meio ambiente. $\mathrm{O}$ consumidor final também pode ser afetado indiretamente, pela depreciação da qualidade nutricional do alimento, podendo ter níveis de resíduos acima dos limites toleráveis para o consumo (GRAVENA, 2003).

A aplicação de inseticidas não é capaz de eliminar todos os insetos presentes nas lavouras. Normalmente, os produtos mais eficientes controlam cerca de $95 \%$ da população. Estudos indicaram que o uso constante de um inseticida ou inseticidas de um mesmo grupo químico selecionam populações resistentes. Considera-se bom o manejo que, ao final do ciclo, resulte em no máximo $10 \%$ de frutos danificados (MEDEIROS, 2007).

Segundo EMBRAPA (2003), num programa de rotação de inseticidas, cada um deve ser utilizado por um período de 28 dias para cobrir aproximadamente uma geração da praga. Inseticidas piretróides e fosforados devem ser utilizados preferencialmente nos períodos de menor atividade de adultos. Com isso, a seleção de populações resistentes ocorrerá apenas em um estágio de vida do inseto, isto é, na fase larval.

Objetivou-se com este trabalho avaliar a eficácia do controle da traça-dotomateiro utilizando um pulverizador costal manual com três volumes de pulverização 300,400 e $500 \mathrm{~L} \mathrm{ha}^{-1}$ e duas doses do inseticida Indoxacarbe (100 e 50\% da dose recomendada do inseticida).

\section{MATERIAL E MÉTODOS}

O trabalho foi conduzido em uma lavoura comercial de tomate, cultivar Santa Clara, no município de Coimbra-MG, localizado na microrregião de Viçosa (Latitude 2051'24" S, Longitude 42 48'10" W, e altitude de 720 metros), utilizando o pulverizador costal manual, da marca Jacto, modelo PJH com capacidade para $20 \mathrm{~L}$.

$\mathrm{O}$ espaçamento médio, entre linhas, das plantas era de $1,00 \mathrm{~m}$, com altura média da cultura de 1,69 m e largura de copa médio de $0,53 \mathrm{~m}$. Foram utilizados três volumes de pulverização (VP), correspondentes a 300 , 400 e $500 \mathrm{~L} \mathrm{ha}^{-1}$ nas velocidades de caminhamento do aplicador de 1,6;1,2 e $0,96 \mathrm{~km} \mathrm{~h}^{-1}$ respectivamente. Além de duas diferentes doses do inseticida Indoxacarbe (100 e $50 \%$ da dose recomendada). A dose recomendada para o controle da traça do

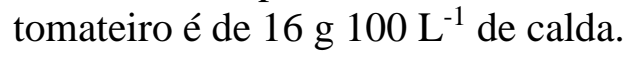

A aplicação do produto utilizando o pulverizador costal manual foi realizada 
após prévia determinação dos três diferentes volumes de calda, baseado no método TRV (Tree Row Volume).

Foi utilizada a ponta de pulverização do tipo leque AIXR 11002 da Marca Teejet ${ }^{\circledR}$ na pressão de 2 bar, mantida por um regulador de mola.

Foram estudados três volumes de pulverização e duas doses do inseticida constituindo um fatorial 3 X 2 num total de 6 tratamentos, os mesmos estavam dispostos no delineamento inteiramente casualizado com 3 repetições, totalizando 18 unidades experimentais.

Durante a coleta das folhas para avaliação da mortalidade das traças do tomateiro, o dossel foi dividido em dois terços (ápice e base) e em cada terço foram considerados duas diferentes profundidades (externa $-\mathrm{P}_{1}$ e interna $-\mathrm{P}_{2}$ ).

Para a medição da velocidade do vento utilizou-se um termo anemômetro digital marca INSTRUTHERM, modelo TAFR-180. A temperatura e umidade relativa foram medidas por um psicrômetro "METEORO INSTRUMENTOS - M-II".

Anteriormente às aplicações, em laboratório, traças foram inoculadas em folíolos de tomate, num total de quatro traças de $2^{\circ}$ e $3^{\circ}$ ínstares, por folíolo, acondicionados em sacos plástico de polietileno. Transcorrendo-se 12 horas verificou-se que todas as traças penetraram nos folíolos do tomateiro.

Em campo, a cada nível do dossel, foi colocado um folíolo inoculado, fixado nas posições do dossel da planta com um alfinete. Decorridos cerca de uma hora, os folíolos foram retirados de cada uma das posições do dossel e acondicionados em sacos de polietileno devidamente identificados.

A mortalidade das traças foi avaliada após 24 e 48 horas, contando em cada folíolo, afixado e depois destacado, o número de traças vivas e mortas.
Os dados foram submetidos à Análise de Variância e de Regressão. Os modelos foram escolhidos baseando-se na significância dos coeficientes de regressão utilizando-se o teste Tukey, adotando-se o nível de $5 \%$ de probabilidade. Foi utilizado o programa computacional SAEG 9.1 (SAEG, 2007).

\section{RESULTADOS E DISCUSSÃO}

O valor de TRV, correspondente ao volume do dossel da cultura do tomateiro, foi de $8983,5 \mathrm{~m}^{3} \mathrm{ha}^{-1}$.

A velocidade do vento variou entre 2,5 e $8,9 \mathrm{~m} \mathrm{~s}^{-1}$, a temperatura entre 27 e 27,2 ${ }^{\circ} \mathrm{C}$ e a umidade relativa entre 63 e $67 \%$.

Foi feita a análise de variância da mortalidade das traças após 24 e 48 horas de acordo com a dose do produto aplicado, volume de pulverização e partes da folha na copa do tomateiro (Tabela 1).

Verifica-se que houve interação significativa entre os fatores avaliados (posições, volumes e doses). Também houve interação significativa para o fator doses na avaliação após 24 horas e interação doses $\mathrm{x}$ volume, posições da planta e posições $\mathrm{x}$ volumes para avaliação após 24 e 48 horas.

Com os resultados obtidos, optou-se pelo estudo, através do desdobramento, das interações volumes/doses, doses/volumes e posições/doses.

Para o desdobramento volumes/doses, considerou-se a dose como fator quantitativo e desta forma realizou-se a análise através de regressão. Já para os fatores doses/volumes e posições/doses as médias foram comparadas utilizando-se o teste de Tukey, ao nível de $5 \%$ de probabilidade.

Foram ajustadas as equações das regressões na interação do volume/dose em cada uma das partes analisadas na planta (Tabela 2). 
Tabela 1. Resumo da análise de variância da mortalidade das traças do tomateiro após 24 e 48 horas utilizando o inseticida Indoxacarbe de acordo com a dose aplicada (D), volume de pulverização (VP) e sua posição nas folhas no tomateiro (P).

\begin{tabular}{lccc}
\hline \multirow{2}{*}{ Fator } & \multirow{2}{*}{ GL } & \multicolumn{2}{c}{ Quadrados médios } \\
\cline { 3 - 4 } & 2 & 24 horas & 48 horas \\
\hline VP & 1 & $2,625^{\mathrm{ns}}$ & $3,4305^{\mathrm{ns}}$ \\
D & 2 & $10,125^{*}$ & $3,125^{\mathrm{ns}}$ \\
D x V & 12 & $5,5417^{*}$ & $7,125^{*}$ \\
Resíduo (a) & 3 & 6,0139 & 4,667 \\
P & 3 & $0,08794^{* *}$ & $7,9028^{* *}$ \\
P x D & 6 & $2,2917^{*}$ & $0,162^{\mathrm{ns}}$ \\
P x V & 3 & $4,6157^{* *}$ & $1,4305^{*}$ \\
P x V x D & 36 & 0,8287 & $2,8287^{* *}$ \\
Resíduo (b) & & 124,97 & 0,7222 \\
\hline CV (\%) Parcela & & 50,809 & 95,422 \\
CV (\%) Subparcela & & & 37,539 \\
\hline
\end{tabular}

Analisando os resultados da análise de regressão (Tabela 3), observou-se que a mortalidade das traças após 24 e 48 horas, adotando-se $50 \%$ da dose, recomendada do inseticida para as posições seguiu o modelo linear, em que o modelo da equação ajustada é o valor da média de cada fator; para a posição ápice interno o modelo quadrático foi o que melhor se ajustou. Como a equação ajustada para a maioria das variáveis analisadas foi linear, não se apresentou $\mathrm{o}$ valor de $\mathrm{R}^{2}$.

Aplicando-se $100 \%$ da dose recomendada, a mortalidade das traças após 24 e 48 horas em todos os setores do dossel seguiu o modelo linear mostrando que independente do volume aplicado não há diferença no controle da praga.

Foi calculada a média da mortalidade das traças do tomateiro após 24 e 48 horas para cada volume estudado (300, 400 e $500 \mathrm{~L} \mathrm{ha}^{-}$ ${ }^{1}$ ) (Tabela 3).

Nas quatro posições da planta, verificou-se que não houve diferença significativa quando se usou um volume de pulverização de 300 L ha-1, analisando a mortalidade das traças após 24 e 48 horas e as duas doses $(50 \%$ e $100 \%$ da dose recomendada) do inseticida Indoxacarbe (Tabela 3).

Este resultado mostra que independente da parte ser externa ou interna obteve-se mortalidade das traças. Analisando a mortalidade das traças após 24 e 48 horas e as duas doses $(50 \%$ e $100 \%$ da dose recomendada) do inseticida Indoxacarbe houve diferença significativa, sendo que a menor mortalidade foi na posição ápice interno para as duas avaliações.

Utilizando-se $50 \%$ e $100 \%$ da dose recomendada, verificou-se que com a mortalidade após 24 e 48 horas não diferiu significativamente quando se usou volume de pulverização de $400 \mathrm{~L} \mathrm{ha}^{-1}$ em todas as posições analisadas.

Houve diferença significativa quando se usou este volume de aplicação nos setores base interna e externa, com maior mortalidade das traças. 
Tabela 2. Análise de regressão da mortalidade das traças do tomateiro após 24 e 48 horas da pulverização, considerando as doses $(100 \%$ e $50 \%$ da dose recomendada) do inseticida.

\begin{tabular}{|c|c|c|c|c|}
\hline Dose (\%) & Posições & Tempo & Equação Ajustada & $\mathbf{R}^{2}$ \\
\hline \multirow{8}{*}{50} & \multirow{2}{*}{ Ápice Externo } & $24 \mathrm{~h}$ & $\hat{y}=2,0000$ & - \\
\hline & & $48 \mathrm{~h}$ & $\hat{y}=2,5556$ & - \\
\hline & \multirow{2}{*}{ Ápice Interno } & $24 \mathrm{~h}$ & $\hat{y}=0,7778$ & - \\
\hline & & $48 \mathrm{~h}$ & $\hat{y}=1,4444$ & - \\
\hline & \multirow{2}{*}{ Base Externa } & $24 \mathrm{~h}$ & $\hat{y}=1,7778$ & - \\
\hline & & $48 \mathrm{~h}$ & $\hat{y}=2,6667$ & - \\
\hline & \multirow{2}{*}{ Base Interna } & $24 \mathrm{~h}$ & $\hat{y}=-33,333+0,18333 v-0,0002333 v^{2} * *$ & 0,6842 \\
\hline & & $48 \mathrm{~h}$ & $\hat{\mathrm{y}}=-21,333+0,126667 \mathrm{v}-0,0001667 \mathrm{v}^{2} * *$ & 0,6727 \\
\hline \multirow{8}{*}{100} & \multirow{2}{*}{ Ápice Externo } & $24 \mathrm{~h}$ & $\hat{\mathrm{y}}=2,7778$ & - \\
\hline & & $48 \mathrm{~h}$ & $\hat{y}=3,222$ & - \\
\hline & \multirow{2}{*}{ Ápice Interno } & $24 \mathrm{~h}$ & $\hat{y}=1,5556$ & - \\
\hline & & $48 \mathrm{~h}$ & $\hat{y}=1,7778$ & - \\
\hline & \multirow{2}{*}{ Base Externa } & $24 \mathrm{~h}$ & $\hat{y}=2,6667$ & - \\
\hline & & $48 \mathrm{~h}$ & $\hat{y}=2,8889$ & - \\
\hline & \multirow{2}{*}{ Base Interna } & $24 \mathrm{~h}$ & $\hat{y}=1,6667$ & - \\
\hline & & $48 \mathrm{~h}$ & $\hat{y}=2,0000$ & - \\
\hline
\end{tabular}

Quando se usou volume de aplicação de $500 \mathrm{~L} \mathrm{ha}^{-1}$ a mortalidade das traças após 24 horas apresentou diferença para as posições do dossel ápice interno e base externa, e para mortalidade das traças após 48 horas houve diferença nas posições: ápice interno e base interna.

Os resultados obtidos de mortalidade se explicam devido ao fato de as aplicações serem realizadas utilizando-se de um pulverizador hidráulico, pois as gotas tem maior facilidade de chegar à parte externa do que à parte interna do dossel das plantas, principalmente no ápice, devido à altura do tomateiro, com isto não chegando produto na parte interna. Para as gotas atingirem a profundidade interna do dossel da planta, elas precisam ultrapassar a barreira externa de folhas tendendo a ficar retidas e não atingirem a parte interna do dossel. 
Tabela 3. Mortalidade das traças do tomateiro (número de traças mortas) após 24 e 48 horas com volume de pulverização de 300 L ha-1 nas posições das plantas e com 50\% e $100 \%$ da dose recomendada do inseticida Indoxacarbe.

\begin{tabular}{|c|c|c|c|c|c|}
\hline \multirow{4}{*}{ Posições } & \multirow{4}{*}{ Volume de pulverização $\left(\mathrm{L} \mathrm{ha}^{-1}\right)$} & \multicolumn{4}{|c|}{ Mortalidade (h) } \\
\hline & & \multicolumn{4}{|c|}{ Doses $(\%)$} \\
\hline & & \multicolumn{2}{|c|}{24} & \multicolumn{2}{|c|}{48} \\
\hline & & 50 & 100 & 50 & 100 \\
\hline Ápice Externo & & $2,00 \mathrm{a}$ & $2,67 \mathrm{a}$ & $2,67 \mathrm{a}$ & $3,00 \mathrm{a}$ \\
\hline Ápice Interno & \multirow{3}{*}{300} & $1,67 \mathrm{a}$ & $0,00 \mathrm{~b}$ & $2,33 \mathrm{a}$ & $0,67 \mathrm{~b}$ \\
\hline Base Externa & & $1,00 \mathrm{a}$ & $2,67 \mathrm{a}$ & $2,33 \mathrm{a}$ & $3,00 \mathrm{a}$ \\
\hline Base Interna & & $0,67 \mathrm{a}$ & $1,67 \mathrm{a}$ & $1,67 \mathrm{a}$ & $2,00 \mathrm{ab}$ \\
\hline Ápice Externo & \multirow{4}{*}{400} & $0,67 \mathrm{bc}$ & $2,33 \mathrm{a}$ & $1,33 \mathrm{a}$ & $2,67 \mathrm{a}$ \\
\hline Ápice Interno & & $0,33 \mathrm{c}$ & $1,33 \mathrm{a}$ & $1,33 \mathrm{a}$ & $1,33 \mathrm{a}$ \\
\hline Base Externa & & $3,00 \mathrm{a}$ & $1,67 \mathrm{a}$ & $3,00 \mathrm{a}$ & $1,67 \mathrm{a}$ \\
\hline Base Interna & & $2,67 \mathrm{ab}$ & $1,33 \mathrm{a}$ & $2,67 \mathrm{a}$ & $1,33 \mathrm{a}$ \\
\hline Ápice Externo & \multirow{4}{*}{500} & $3,33 \mathrm{a}$ & $3,33 \mathrm{a}$ & $3,67 \mathrm{a}$ & $4,00 \mathrm{a}$ \\
\hline Ápice Interno & & $0,33 \mathrm{~b} \mathrm{~B}$ & 3,33 a $A$ & $0,67 \mathrm{~b} B$ & 3,33 a $A$ \\
\hline Base Externa & & $1,33 \mathrm{ab} B$ & 3,67 a $A$ & 2,67 a $A$ & 4,00 a $\mathrm{A}$ \\
\hline Base Interna & & $0,00 \mathrm{~b} \mathrm{~A}$ & 2,00 a $A$ & $0,33 \mathrm{~b} \mathrm{~B}$ & 2,67 a $A$ \\
\hline
\end{tabular}

* Médias seguidas pela mesma letra maiúscula nas linhas e minúsculas nas colunas não diferem a 5\% de probabilidade, segundo o teste de Tukey.

\section{CONCLUSÕES}

O inseticida Indoxacarbe foi um bom parâmetro para avaliar a mortalidade da traça do tomateiro para os volumes utilizados. Pode-se controlar a traça do tomateiro com volumes de pulverização menores que os recomendados pelo fabricante. Independente do volume aplicado, o desdobramento volume de pulverização/dose seguiu o modelo linear. Com o experimento independente da dose utilizada, a mortalidade das traças foi estatisticamente igual, podendo se utilizar menor quantidade de inseticida. Para todos os volumes analisados as partes externas, superior, mediana e inferior apresentaram maior mortalidade das traças do tomateiro.

\section{REFERÊNCIAS BIBLIOGRÁFICAS}

ALVINO, C. A.; ULIAN, I. Z.; DIAS, J. C.; CORREIA, J. C.; GODOY, A. R. 2009. Controle da traça do tomateiro. Revista científica eletrônica de agronomia. Ano VII, n. 15, Garça-SP.

ARNÓ, J.; GABARRA, R. 2011. Side effects of selected insecticides on the Tuta absoluta (Lepidoptera: Gelechiidae) predators Macrolophus pygmaeus and Nesidiocoris tenuis 
(Hemiptera: Miridae). Journal of Pest Science. v. 84, p. 513-520.

DESNEUX, N.; LUNA, M. G.; GUILLEMAUD, T. URBANEJA, A. 2011. The invasive South American tomato pinworm, Tuta absoluta, continues to spread in Afro-Eurasia and beyond: the new threat to tomato world production. Journal of Pest Science. v. 84, p 403-408.

EMBRAPA HORTALIÇAS. 2010. Sistemas de Produção, jan. 2003. Disponível em: <http://sistemasdeproducao.cnptia.embra pa.br/FontesHTML/Tomate/TomateIndst rial/expediente.htm>. Acesso em 5 jan. 2010.

EPPO. 2006. European and Mediterranean Plant Protection Organization. Data sheets on quarantine pests. Tuta absoluta. Disponível em: <http://www.eppo.org/QUARANTINE/i nsects/Tuta_absoluta/DS_Tuta_absoluta. pdf $>$. Acesso em 23 Dez. 2011.

GRAVENA, S.; BENVENGA, S. R. 2003. Manual prático para manejo de pragas do tomate. Jaboticabal: Gravena, 143p.

HODGES, R.W. 1998. Gelechioidea. In: Kristensen, N.P. (ed.), Lepidoptera, moths and butterflies. Handbook of zoology/Handbuch der Zoologie. Berlin and New York.

IOST, C. A. R.; FERREIRA, M. C.; MARTINELLI, N. M.; MACAGNAN, D. H. B. 2008. Avaliação de volumes de calda proporcionados por diferentes pontas de pulverização no controle de Tuta absoluta (Meirick, 1917) (Lepidoptera: Gelechiidae) em tomate rasteiro. Acta Scientiarum Agronomy, v. 30 , p. 619-624.
MEDEIROS, M.A. 2007. O papel da biodiversidade no manejo da traçado-tomateiro Tuta absoluta (Meyrick, 1917) (Lepidoptera: Gelechiidae). Tese de Doutorado, Universidade de Brasília. 145 p.

OLIVEIRA, A. C. R.; VELOSO, V. R. S.; BARROS, R. G.; FERNANDES, P. M.; SOUZA, E. R. B. 2008. Captura de Tuta absoluta (Meyrick) (Lepidoptera: Gelechiidae) com armadilha luminosa na cultura do tomateiro tutorado. Pesquisa Agropecuária Tropical. v. 38, n. 3, p. 153-157.

SAEG. 2007. Sistema para Análises Estatísticas, Versão 9.1: Fundação Arthur Bernardes - UFV - Viçosa.

THOMAZINI, A. P. B. W; VENDRAMIM, J. D; BRUNHEROTTO, R., LOPES, M. A T.R. 2001. Efeito de genótipos de tomateiro sobre a biologia e oviposição de Tuta absoluta (Meyrick) (Lep.: Gelechiidae). Neotropical Entomology, Londrina, v.30, n.2, p. 283-288.

Recebido em: 18/9/2013 Aceito para publicação em: 19/2/2014 